\title{
PERAN TERAPI AKUPUNKTUR PADA CARPAL TUNNEL SYNDROME
}

\author{
ROLE OF ACUPUNCTURE THERAPY IN CARPAL TUNNEL SYNDROME
}

Wahyuningsih Djaali, *** Christina Lanny Simadibrata, * Irma Nareswari, * Dwi Rachma Helianthi, * Kemas Abdurrohim*

\begin{abstract}
Carpal tunnel syndrome (CTS) is the most common peripheral neuropathy. In establishing a diagnosis of CTS, it requires several examinations that cannot stand alone. Symptoms from the anamnesis and signs of physical examination, such as Tinel test, Phalen test, press provocation examination, hand elevation examination and motor examination are needed. Nerve conduction velocity (NCV) investigation is also needed to diagnose CTS. Nevertheless, the clinical diagnosis of CTS can be done based on symptom history and physical examination using criteria by Rempel. Acupuncture is a modality of non-pharmacological therapy performed by using fine needles at the acupuncture points. Acupuncture can improve the clinical symptoms of CTS patients through a mechanism of activation of the area in the brain that plays a role in sensory perception, through anti-inflammatory and anti-nociceptive mechanisms, and through mechanisms of protective effects on neural networks, thus providing therapeutic effects on neurological disorders due to CTS. By looking at the acupuncture mechanism, acupuncture can be a therapeutic choice for CTS to avoid the long-term side effects of medical therapy.
\end{abstract}

Keywords: Acupuncture, carpal tunnel syndrome

\section{ABSTRAK}

Carpal tunnel syndrome (CTS) merupakan neuropati perifer yang paling umum terjadi. Dalam menegakkan diagnosis CTS dibutuhkan beberapa pemeriksaan yang tidak dapat berdiri sendiri. Dibutuhkan gejala dari anamnesis, tanda dari pemeriksaan fisik, yaitu tes Tinel, tes Phalen, pemeriksaan provokasi tekan, pemeriksaan elevasi tangan dan pemeriksaan motorik. Juga dibutuhkan pemeriksaan penunjang kecepatan hantan saraf (KHS) untuk mendiagnosis pasti CTS. Sedangkan diagnosis klinis CTS dapat dilakukan berdasarkan anamnesis gejala dan pemeriksaan fisik dengan menggunakan kriteria oleh Rempel. Akupunktur merupakan modalitas terapi non-farmakologis yang dilakukan dengan penjaruman menggunakan jarum halus pada titik akupunktur. Akupunktur dapat memperbaiki gejala klinis pasien CTS melalui mekanisme aktivasi area di otak yang berperan pada persepsi sensorik, melalui mekanisme anti-inflamasi dan antinosiseptif, dan melalui mekanisme efek protektif pada jaringan saraf, sehingga memberikan efek terapeutik pada kelainan neurologis akibat CTS. Dengan melihat mekanisme akupunktur tersebut maka akupunktur dapat menjadi pilihan terapi pada CTS untuk menghindari efek samping jangka panjang dari terapi medikamentosa.

Kata kunci: Akupunktur, carpal tunnel syndrome

*Departemen Medik Akupunktur FK Universitas Indonesia/RSUPN Dr. Cipto Mangunkusumo, Jakarta; **Universitas Negeri Jakarta, Jakarta. Korespondensi: inchy86@yahoo.com.

\section{PENDAHULUAN}

Carpal tunnel syndrome (CTS) adalah salah satu bentuk neuropati nervus medianus yang paling sering terjadi. Carpal tunnel syndrome terjadi akibat adanya penyempitan pada terowongan karpal di pergelangan tangan. Hal ini dapat disebabkan oleh inflamasi pada tendon otot atau pada nervus medianus. $^{1-2}$ Prevalensi CTS bervariasi antara $0,125-1 \%$ dan $5-16 \%$ bergantung dari kriteria diagnosis yang digunakan. Carpal tunnel syndrome memengaruhi $4-5 \%$ populasi terutama pada usia $40-$ 60 tahun, dan tingkat prevalensi CTS lebih tinggi terjadi pada perempuan $(9,2 \%)$ dibandingkan pada laki-laki (6\%) di antara usia 45-60 tahun. ${ }^{2}$
Tata laksana yang umum dilakukan untuk CTS adalah pemakaian wrist splint terutama pada malam hari, atau dengan terapi medikamentosa kortikosteroid seperti Metilprednisolon, Prednison, dan Deksametason. Tetapi kortikosteroid ini mempunyai beberapa efek samping apabila digunakan dalam jangka waktu lama, antara lain terjadinya imunosupresi dan bengkak di wajah (moon face)..$^{3-4}$

Akupunktur merupakan salah satu modalitas terapi non-farmakologis yang dilakukan dengan penjaruman menggunakan jarum halus pada titiktitik akupunktur. Akupunktur pada titik akupuntur dapat mengaktifkan serabut saraf dan reseptor aferen perifer, menghasilkan interaksi sensorik di berbagai 
tingkat sistem saraf pusat dan melepaskan berbagai transmitter dan modulator, sehingga menghasilkan sinyal anti-inflamasi, sinyal neuroendokrin dan neuroimun. $^{5}$

\section{PEMBAHASAN}

\section{Carpal Tunnel Syndrome}

Carpal tunnel syndrome (CTS) adalah salah satu bentuk neuropati nervus medianus yang paling sering terjadi. Carpal tunnel syndrome memengaruhi 4-5\% populasi terutama pada usia 40-60 tahun. Insidensi dan prevalensi dari CTS sangatlah bervariasi bergantung dari kriteria diagnostik yang digunakan. Secara klinis, dikatakan satu dari sepuluh orang menderita CTS. ${ }^{2}$

Patofisiologi CTS adalah neuropati yang terjadi akibat adanya entrapment atau jebakan saraf, yang melibatkan terjadinya kompresi dan traksi. Kompresi dan traksi pada saraf menyebabkan kelainan mikrosirkulasi intraneural, lesi pada axon dan selubung myelin, dan perubahan pada jaringan penyokong di terowongan karpal. Entrapment pada saraf perifer dapat terjadi sebagai akibat dari penyempitan ruangan yang dilalui oleh saraf tersebut, sehingga terjadi perubahan pada fungsi atau bahkan terjadi kerusakan di tempat terkompresinya saraf dan di sisi distalnya. Entrapment pada nervus medianus adalah contoh yang paling sering terjadi pada kelainan ini. Mekanisme patofisiologi yang mungkin terjadi pada kelainan CTS adalah terjadinya peningkatan tekanan di terowongan karpal, kelainan mikrosirkulasi nervus medianus, perubahan jaringan penyokong nervus medianus dan hipertrofi jaringan sinovial pada terowongan karpal. ${ }^{6}$

Oleh karena nervus medianus memberikan persarafan sensorik pada kulit di jari-jari tangan, maka keluhan seperti parestesia, hipoestesia, dan anestesia dapat muncul pada jari I, II, III dan sisi medial jari IV. Sedangkan cabang kutaneus palmaris yang memberikan persarafan sensorik pada bagian palmar, berjalan di sisi luar dari terowongan karpal, sehingga sensasi pada bagian palmar tidak terganggu. Selain persarafan sensorik, nervus medianus juga memberikan persarafan motorik pada ketiga otot thenar, sehingga keluhan penurunan kekuatan pada otot-otot thenar juga dapat terjadi, yang secara klinis ditandai dengan berkurangnya kemampuan seseorang melakukan gerakan adduksi dan abduksi ibu jari. ${ }^{1}$

Terdapat beberapa pemeriksaan untuk mendiagnosis CTS, tetapi pemeriksaan-pemeriksaan tersebut tidak dapat berdiri sendiri. Dibutuhkan gejala, tanda dan pemeriksaan penunjang untuk mendiagnosis CTS. Pemeriksaan fisik terdiri dari tes Tinel, tes Phalen, pemeriksaan provokasi tekan, pemeriksaan elevasi tangan dan pemeriksaan motorik. Diagnosis klinis CTS berdasarkan anamnesis gejala dan pemeriksaan fisik dapat dilakukan dengan menggunakan kriteria oleh Rempel (Tabel 1). ${ }^{7}$ Apabila terdapat keraguan dalam diagnosis klinis CTS maka harus dilakukan diagnosis dengan pemeriksaan elektrofisiologi. Saat ini derajat keparahan CTS berdasarkan elektrodiagnostik yang digunakan adalah derajat keparahan yang dikemukakan oleh Bland ${ }^{8}$ di mana derajat tersebut dibagi menjadi enam tingkatan.

Kuesioner Boston Carpal Tunnel Syndrome Questionnaire (BCTQ) merupakan kuesioner yang dikembangkan khusus untuk menilai derajat keparahan CTS dan menilai fungsional tangan serta pergelangan tangan pada penderita CTS. Format dari kuesioner terdiri dari satu lembar yang berisikan 19 pertanyaan yang dibagi menjadi dua bagian, yaitu bagian tingkat keparahan gejala (11 pertanyaan) dan bagian penilaian status fungsional (8 pertanyaan). Saat ini telah dilakukan uji validitas dan reliabilitas untuk

Tabel 1. Klasifikasi CTS berdasarkan Kriteria Rempel ${ }^{7}$

\begin{tabular}{ll}
\hline \multicolumn{1}{c}{ Klasifikasi CTS } & \multicolumn{1}{c}{ Keluhan dan Gejala } \\
\hline Klasik/Probable & $\begin{array}{l}\text { Mati rasa, baal, kesemutan, rasa panas atau sakit, setidaknya pada 2 jari (jari 1, 2, atau 3). } \\
\text { Rasa sakit pada telapak tangan, pergelangan tangan atau sakit yang menjalar ke bagian prok- } \\
\text { simal dapat terjadi. }\end{array}$ \\
Possible & Kesemutan, mati rasa, rasa terbakar atau sakit, setidaknya pada 1 jari (jari 1, 2, atau 3). \\
Unlikely & Tidak ada keluhan ataupun gejala pada jari 1, 2, dan 3. \\
\hline CTS: carpal tunnel syndrome. &
\end{tabular}


kuesioner ini di RSUPN Dr. Cipto Mangunkusumo, ${ }^{9}$ dengan hasil kuesioner BCTQ versi Bahasa Indonesia valid dan reliabel untuk digunakan sebagai instrumen dalam menilai derajat keparahan gejala dan status fungsional pada CTS.

Tata laksana medikamentosa untuk CTS adalah dengan menggunakan kortikosteroid oral, yaitu prednison 20mg/hari selama 4 minggu, kemudian dilanjutkan $10 \mathrm{mg}$ /hari selama 2 minggu. Tetapi kortikosteroid oral ini mempunyai beberapa efek samping apabila digunakan dalam jangka waktu lama, antara lain terjadinya imunosupresi, peningkatan gula darah pada pasien diabetes, bengkak di wajah (moon face), kenaikan berat badan, psikosis, katarak atau glaukoma, dan osteoporosis. Selain dengan kortikosteroid oral, terapi CTS dapat dilakukan dengan injeksi steroid ke dalam terowongan karpal. Obat injeksi steroid yang dapat digunakan adalah metilprednisolon injeksi dengan dosis 20-40mg. Namun injeksi kortikosteroid intraartikuler ini memiliki beberapa efek samping, antara lain menurunkan kekuatan tulang, atrofi tendon, dan ruptur tendon. ${ }^{3-4}$

\section{Hasil Penelitian Akupunktur pada Carpal Tunnel Syndrome berdasarkan Gambaran fMRI}

Studi beberapa tahun terakhir mengenai CTS menyebutkan bahwa pada CTS dapat terjadi suatu maladaptif neuroplastisitas akibat adanya input aferen yang salah pada kelainan CTS. Neuroplastisitas adalah kemampuan sel-sel saraf di otak dalam melakukan re-organisasi sel, baik secara struktural maupun fungsional. Pembentukan sel saraf baru (neurogenesis), pembentukan sinaps-sinaps baru antar sel saraf, dan penguatan ataupun pelemahan sinaps antar sel saraf, merupakan proses neuroplastisitas yang terjadi di otak yang dapat menyebabkan perubahan struktur maupun fungsi. Neuroplastisitas ini dapat terjadi akibat adanya perubahan pada dendrit, perubahan pada kanal ion membran sel saraf, akibat aktivitas hormonal, aktivitas mikroglia, akibat perubahan regulasi dan transkripsi DNA, dan juga dipengaruhi oleh neurotransmiter.

Pada kerusakan nervus medianus yang terjadi pada CTS akan menyebabkan perubahan pada sistem somatosensorik baik di otak maupun di perifer, yang dapat dinilai pada medula spinalis, batang otak, dan korteks somatosensorik primer. ${ }^{10}$ Pada studi oleh Maeda, ${ }^{11}$ dikatakan terdapat neuroplastisitas fungsional maupun struktural yang terjadi pada korteks somatosensorik primer di otak. Dikatakan bahwa terdapat hubungan antara besarnya jarak separasi interdigit 2 dan 3 pada korteks, dengan tingkat keparahan gejala yang dirasakan pasien. Selain itu, studi lain menyebutkan perubahan neuroplastisitas pada CTS dapat menyebabkan perubahan struktural pada substansia grisea. $^{12}$ Dikatakan bahwa volume subtansia grisea menurun pada CTS dan penurunan tersebut secara spesifik terjadi pada area somatotopik tangan di korteks somatosensorik primer kontralateral. Studi yang juga dilakukan oleh Maeda pada tahun 2016, ${ }^{13}$ menyebutkan tidak hanya korteks somatosensorik primer saja yang mengalami perubahan pada CTS, tetapi juga korteks motorik primer. Dikatakan pada studi tersebut ketebalan korteks somatosensorik primer maupun korteks motorik primer kontralesi berkorelasi dengan keparahan nyeri yang dirasakan pasien CTS.

Teknik imaging otak yang tidak invasif, seperti functional magnetic resonance imaging (fMRI), dapat memberikan informasi bagaimana otak manusia merespons terhadap stimulasi jarum akupunktur. ${ }^{10}$ Hingga saat ini masih sedikit studi yang mengevaluasi bagaimana respons otak terhadap stimulasi jarum akupunktur melalui gambaran fMRI yang menyebabkan berkurangnya gejala pada CTS. Berdasarkan teori terjadinya neuroplastisitas di otak akibat CTS, dapat dinilai bagaimana akupunktur memberikan efek pada gambaran fMRI otak dengan melihat perubahan area otak yang terjadi akibat stimulasi akupunktur.

Salah satunya adalah studi oleh Napadow, yang menilai neuroplastisitas pada korteks somatosensorik saat jari-jari distimulasi secara elektrik maupun secara mekanik. Pada studi ini, tampak adanya ekspansi dari area korteks yang memproyeksikan jari, hal ini berhubungan dengan kompresi pada nervus medianus di tingkat karpal. Ekspansi ini dilaporkan menurun setelah dilakukan terapi akupunktur selama lima 
minggu. Kemudian studi oleh Zhang, menunjukkan adanya respons fMRI terhadap stimulasi listrik transkutaneus yang terjadi pada beberapa area di otak seperti korteks somatosensorik sekunder, insula, dan korteks motorik primer yang dikatakan berkaitan dengan penurunan nyeri yang dirasakan. ${ }^{10}$

Pada berbagai penelitian yang melihat gambaran fMRI pada pasien CTS yang menjalani terapi akupunktur, dikatakan bahwa akupunktur memberikan efek berupa aktivasi beberapa area otak yaitu insula, cingulum, korteks somatosensorik primer, dan korteks prefrontal pada hasil gambaran fMRI. ${ }^{21}$ Salah satunya adalah studi oleh Napadow, yang menyebutkan terapi akupunktur selama lima minggu memberikan efek aktivasi korteks somatosensorik primer dan korteks prefrontal. Di mana korteks somatosensorik primer dan korteks prefrontal ini merupakan korteks yang berperan utama dalam persepsi sensorik, sehingga secara klinis terjadi penurunan gejala sensorik yang dirasakan oleh pasien CTS.

\section{Mekanisme Akupunktur pada Carpal Tunnel Syndrome}

Mekanisme akupunktur pada CTS yang terlihat pada gambaran fMRI adalah terdapatnya aktivasi beberapa area di otak, antara lain korteks somatosensorik primer, korteks somatosensorik sekunder dan korteks prefrontal, yang terlihat setelah terapi akupunktur. Area-area otak ini berperan pada proses persepsi sensorik di mana gejala utama yang dirasakan oleh pasien CTS adalah gejala sensorik, seperti parestesi dan nyeri. Teori mengenai terjadinya neuroplastisitas di otak akibat CTS yang ditunjukkan dengan adanya perubahan struktural maupun fungsional pada area otak yang memproyeksikan daerah kelainan saraf (dalam kasus ini adalah daerah tangan dan jari-jari), dan dengan terlihatnya aktivasi beberapa area otak setelah stimulasi akupunktur, dan juga adanya korelasi yang menujukkan perubahan gejala sensorik yang dirasakan pasien CTS dengan perubahan gambaran fMRI area otak, menunjukkan bahwa akupunktur berpengaruh terhadap pengurangan keparahan gejala yang dirasakan pasien CTS..$^{10,14-15}$

Dari beberapa studi lain juga menyebutkan mengenai efek akupunktur terhadap CTS adalah melalui efek anti-inflamasi dan anti-nosiseptif. Dikatakan akupunktur telah terbukti meningkatkan ekspresi sitokin anti-inflamasi seperti IL-10, dan mengurangi sitokin pro-inflamasi seperti TNF- $\alpha$, IL-1 $\beta$ dan IL-6. Akupunktur juga menekan aktivasi faktor transkripsi nuclear factor kappa $B(\mathrm{NF}-\kappa \mathrm{B})$ yang merupakan faktor transkripsi utama dalam mengaktifkan gen-gen yang berhubungan dengan inflamasi. ${ }^{5}$ Modulasi saraf berperan dalam proses terjadinya inflamasi sebagai reaksi yang dilakukan oleh sistem imun bawaan tubuh. Otak dan sistem imun bawaan tubuh membentuk suatu jaringan dua arah melalui jalur humoral maupun jalur neural, di mana sistem imun berperan sebagai organ sensorik yang menginformasikan ke otak mengenai terjadinya suatu inflamasi dan cedera jaringan, sehingga otak akan merespons dengan membentuk suatu respons inflamasi yang terlokalisasi. Proses ini dimulai saat serabut saraf $\mathrm{C}$ memberi stimulus terhadap pelepasan substansi $\mathrm{P}$ dan agen proinflamasi lainnya, yang menginduksi vasodilatasi dan meningkatkan premeabilitas vaskular untuk terjadinya migrasi leukosit. Respons stres akut melalui sistem saraf simpatis dimediasi secara langsung oleh interaksi "nerve-to-immune-cell" dan secara tidak langsung oleh aksis neuroendokrin adrenal. Terjadinya ikatan katekolamin terhadap reseptor $\beta 2$-adrenergik akan menyebabkan penurunan sekresi sitokin proinflamasi (TNF- $\alpha$, IL-1 $\beta$, IL-6 dan IL-18) dan peningkatan sekresi sitokin anti-inflamasi (IL10), proses ini terjadi melalui "jalur anti-inflamasi kolinergik". Sinyal ini juga akan di-relay ke hipothalamus dan kompleks vagal dorsalis, sehingga terjadilah stimulasi ACTH yang akan mengaktifkan "jalur anti-inflamasi humoral". ${ }^{16}$ Melalui kedua jalur anti-inflamasi inilah akupunktur dapat berperan dalam mengurangi inflamasi yang terjadi.

Carpal tunnel syndrome merupakan neuropati perifer yang paling umum terjadi. Selain melalui mekanisme yang telah disebutkan di atas, akupunktur juga berperan pada neuropati perifer melalui efek protektif pada jaringan saraf, yaitu dengan meningkatnya ekspresi neurotrophic factor (NTF) berupa brain-derived neurotrophic factor (BDNF). ${ }^{17}$ NTF ini terlibat pada berbagai proses perkembangan, 
proliferasi dan maturasi sel saraf. NTF seperti BDNF, nerve growth factor (NGF), dan neurotropin (NT) 3 dan NT-4/5 menjalankan fungsinya dengan berikatan pada reseptor Trk (tropomyosin-related tyrosine kinase), di mana spesifisitas reseptor Trk antara lain adalah TrkA sebagai reseptor NGF, TrkB sebagai reseptor BDNF dan NT-4/5, dan TrkC sebagai reseptor NT-3. Peran akupunktur di sini adalah akupunktur meningkatkan regulasi reseptor Trk sehingga memungkinkan terjadinya peningkatan fungsi berbagai NTF, dan juga akupunktur secara langsung meningkatkan kadar BDNF. ${ }^{5}$ Oleh karena itu akupunktur dapat berperan sebagai stimulator yang mengaktifkan saraf perifer pada titik akupunktur spesifik dan mengindukasi berbagai NTF di otak. Selanjutnya NTF ini akan memicu sinyal autokrin maupun parakrin yang merangsang neurogenesis, sehingga memberikan efek terapeutik pada penyakitpenyakit neurologis (Gambar 1).

\section{Akupunktur pada Carpal Tunnel Syndrome sebagai Pilihan Terapi}

Akupunktur dapat memperbaiki gejala pada CTS yang dapat dinilai berdasarkan kuesioner CTS, salah satunya adalah kuesioner BCTQ (Boston Carpal Tunnel Questionnaire). ${ }^{9,18}$ Selain itu secara objektif, akupunktur juga memperbaiki hasil pemeriksaan KHS, seperti pada kecepatan konduksi sensorik dan latensi motorik. ${ }^{14,19}$ Hal ini didukung oleh pada beberapa penelitian mengenai CTS yang mendapatkan terapi akupunktur, didapatkan gambaran fMRI yang sesuai dengan perbaikan klinis yang dirasakan pasien. ${ }^{10,14}$

Akupunktur dapat berperan pada CTS melalui beberapa mekanisme. Pada pasien CTS yang mendapatkan terapi akupunktur didapatkan adanya gambaran aktivasi pada beberapa area di otak, seperti korteks somatosensorik primer, korteks

PC7 \& TE5 $\rightarrow$ Aktivasi area korteks somatosensorik primer \& sekunder dan korteks prefrontal
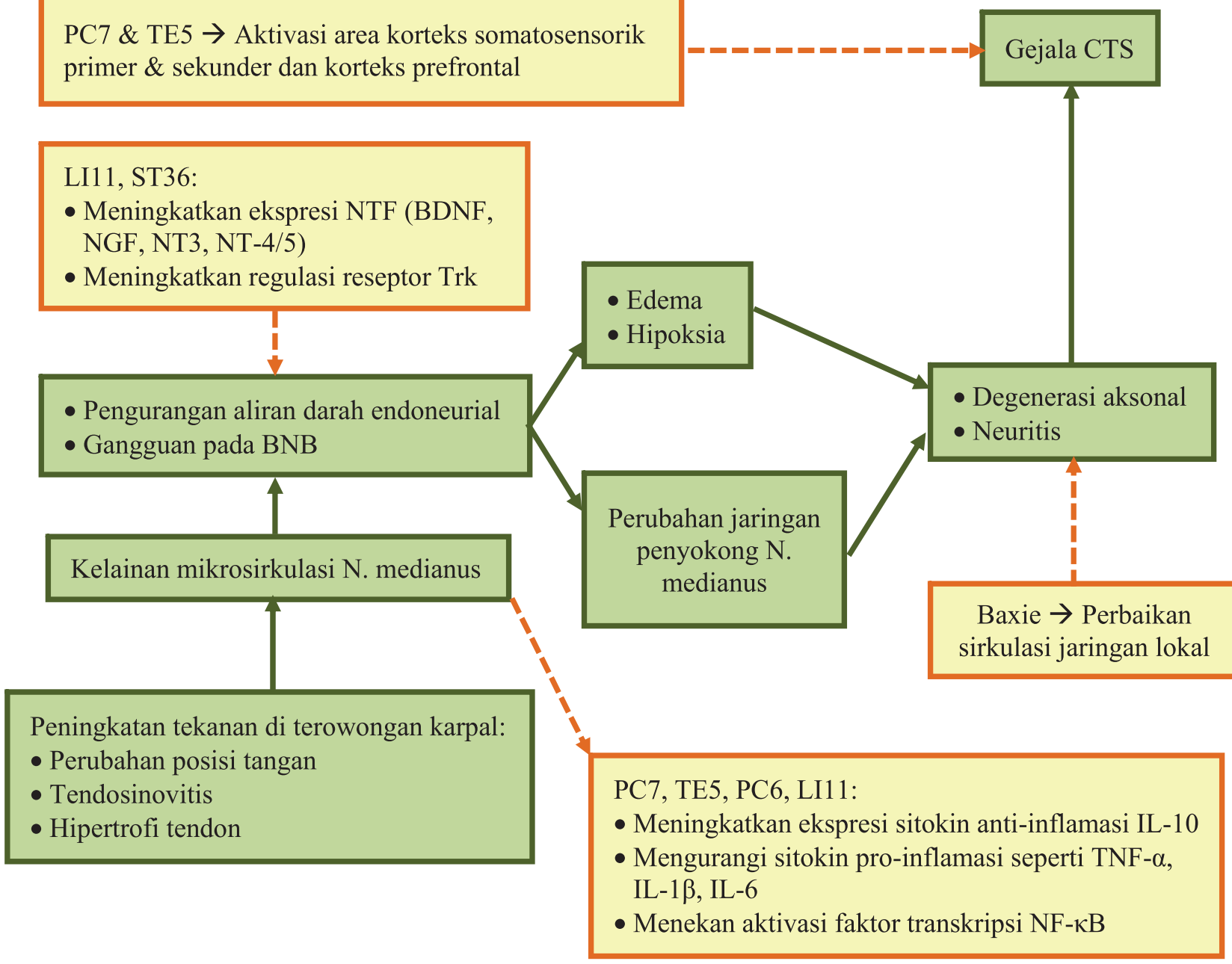

Gambar 1. Mekanisme Akupunktur pada CTS 
Tabel 2. Penelitian Terbaru Mengenai Akupunktur pada CTS

\begin{tabular}{|c|c|c|c|}
\hline Studi & Tujuan & Intervensi & Luaran / Hasil \\
\hline $\begin{array}{l}\text { Hadianfard } \\
\mathrm{dkk}(2014)^{18}\end{array}$ & $\begin{array}{ll}\text { Melihat } & \text { efikasi } \\
\text { akupunktur } & \text { jangka } \\
\text { pendek } & \text { dengan }\end{array}$ & $\begin{array}{l}\text { - Night wrist splint } 1 \text { bulan }+8 \\
\text { sesi akupunktur }(2 \mathrm{x} / \mathrm{minggu} \\
\text { selama } 4 \mathrm{mg}) \text { pada titik PC7, }\end{array}$ & $\begin{array}{l}\text { - Perbaikan yang signifikan pada VAS, } \\
\text { skor BCTQ (fungsi dan gejala), } \\
\text { dan hasil elekrodiagnostik (kecuali }\end{array}$ \\
\hline RCT & $\begin{array}{l}\text { kompresi, dibandingkan } \\
\text { dengan terapi obat anti- } \\
\text { inflamasi }\end{array}$ & $\begin{array}{l}\text { PC4, PC6, PC8, HT2, HT7, } \\
\text { HT8, LU9 dan LI11. } \\
\text { - Night wrist splint } 1 \text { bulan }+ \\
\text { 400mg ibuprofen }(3 \mathrm{x} / \text { hari } \\
\text { selama } 10 \text { hari }) .\end{array}$ & $\begin{array}{l}\text { latensi motorik distal) pada grup } \\
\text { akupunktur lebih baik dibandingkan } \\
\text { grup obat (ibuprofen). }\end{array}$ \\
\hline $\begin{array}{l}\text { Ural dkk } \\
(2017)^{19}\end{array}$ & $\begin{array}{lr}\text { Mengevaluasi } & \text { efek } \\
\text { akupunktur pada } & \text { CSA } \\
\text { saraf medianus dan }\end{array}$ & $\begin{array}{l}\text { - Night wrist splint } 1 \text { bulan }+10 \\
\text { sesi akupunktur }(2-3 \mathrm{x} / \mathrm{minggu} \\
\text { selama } 4 \mathrm{mg}) \text { pada titik PC7, }\end{array}$ & $\begin{array}{l}\text { - Skor VAS, DHI, Quick DASH, } \\
\text { dan pengukuran elektrofisiologi } \\
\text { meningkat pada kedua kelompok. }\end{array}$ \\
\hline $\mathrm{RCT}$ & $\begin{array}{l}\text { mencari tahu korelasi } \\
\text { antara perubahan klinis/ } \\
\text { KHS dgn USG pada } \\
\text { pasien CTS }\end{array}$ & $\begin{array}{l}\text { PC4, PC6, PC8, HT2, HT7, } \\
\text { HT8, LU9, dan LI11, selama } 25 \\
\text { menit. } \\
\text { - Night wrist splint } 1 \text { bulan. }\end{array}$ & $\begin{array}{l}\text { - CSA (cross-sectional area) saraf } \\
\text { medianus secara signifikan menurun } \\
\text { pada kelompok akupunktur. } \\
\text { - Setelah terapi akupunktur, pasien } \\
\text { dengan CTS dapat mengalami } \\
\text { perbaikan klinis maupun perbaikan } \\
\text { morfologi. }\end{array}$ \\
\hline
\end{tabular}

Maeda dkk Melihat efek Akupunktur 16x selama 8 minggu - Ketiga kelompok intervensi $(2017)^{14} \quad$ elektroakupunktur (EA) dengan follow up 3 bulan, pada 3 akupunktur didapatkan penurunan terhadap keparahan kelompok: pada keparahan gejala.

RCT gejala, perbaikan KHS, - Akupunktur lokal: EA $2 \mathrm{~Hz}$ - Kelompok akupunktur lokal dan peningkatan fungsi 20 menit pada PC7 dan TE5 dan distal lebih superior dalam korteks somatosensorik ipsilateral, dan MA pada HT3, memperbaiki hasil KHS. primer pd fMRI PC3, LU5, LI10, SI4, LI5 - Kelompok akupunktur dapat ipsilateral. mempertahankan perbaikan s.d. 3

- Akupunktur distal: EA $2 \mathrm{~Hz}$ bulan.

20 menit pada SP6 dan LR4 - Kelompok akupunktur lokal dan kontralateral, dan MA pada distal sama-sama meningkatkan GB34, KI3, SP5 kontralateral. perbaikan fungsi saraf medianus di

- Akupunktur sham: 2 titik sham pergelangan tangan, tetapi dengan di aspek ulnar, 1 titik sham di somatotopik yang berbeda pada aspek radial, dan 2 titik sham di korteks somatosensorik primer. kaki kontralateral.

MA: manual akupunktur; EA: elektro akupunktur; CSA: cross-sectional area; USG: ultrasonography; VAS: visual analog scale; DHI: Duruoz Hand Index; DASH: the Disabilities of the Arm, Shoulder and Hand; BCTQ: Boston Carpal Tunnel Syndrome Questionnaire; KHS: kecepatan hantar saraf; fMRI: functional magnetic resonance imaging.

somatosensorik sekunder dan korteks prefrontal, yang sesuai dengan perbaikan gejala sensorik yang dirasakan pasien CTS. ${ }^{10,15}$ Akupunktur juga mempunyai efek anti-inflamasi dan anti-nosiseptif, melalui peningkatan ekspresi sitokin anti-inflamasi seperti IL-10, dan penurunan sitokin pro-inflamasi seperti TNF- $\alpha$, IL-1 $\beta$ dan IL-6. ${ }^{5,16}$ Selain itu, akupunktur dapat berperan pada neuropati perifer seperti CTS melalui efek protektif pada jaringan saraf, yaitu dengan meningkatnya ekspresi neurotrophic factor (NTF) seperti brain-derived neurotrophic factor (BDNF), nerve growth factor (NGF), neurotropin (NT) 3 dan NT$4 / 5$, dan juga melalui peningkatan regulasi reseptor Trk (tropomyosin-related tyrosine kinase) yang merupakan reseptor dari faktor-faktor neurotropik tersebut. $^{5,17}$ Melalui beberapa mekanisme di atas, akupunktur dapat memberikan efek terapeutik pada kelainan neurologis akibat CTS. Mekanisme akupunktur ini salah satunya sama dengan mekanisme dari terapi farmakologi yang dipakai pada terapi CTS, yaitu kortikosteroid seperti Metilprednisolon, Prednison dan Deksametasone. Di mana mekanisme 
steroid yang diinginkan untuk memperbaiki gejala CTS adalah efek anti-inflamasi dari steroid.

Dari berbagai studi mengenai CTS yang mendapatkan terapi akupunktur, pemilihan titik yang paling sering dipakai adalah PC7, TE5, PC6, dan LI11. Pemilihan titik ini sesuai dengan anatomi dan letak kelainan yang terjadi pada nervus medianus. Modalitas akupunktur yang sering digunakan adalah manual akupunktur dan elektro-akupunktur, yang sebagian besar meneliti tentang efek akupunktur terhadap gejala klinis CTS dan hasil pemeriksaan elektrofisiologi nervus medianus. Sedangkan pada penelitian yang menggunakan modalitas laser berupa low level laser therapy (LLLT), sebagian besar lebih terfokus kepada efek akupunktur terhadap gejala nyeri pada pasien CTS.

\section{KESIMPULAN}

Dengan melihat berbagai hasil penelitian akupunktur pada CTS dan mekanisme akupunktur yang memberikan efek terapeutik pada kelainan CTS, maka akupunktur dapat menjadi pilihan terapi pada CTS untuk menghindari efek samping jangka panjang dari terapi medikamentosa CTS.

\section{DAFTAR PUSTAKA}

1. Keith-Moore AF, Anne A. Clinical oriented anatomy. Philadelphia, Pennsylvania: Lippincott Williams and Wilkins; 2010. h. 1-1156.

2. Padua L, Coraci D, Erra C, Pazzaglia C, Paolasso I, Loreti C, dkk. Carpal tunnel syndrome: clinical features, diagnosis, and management. The Lancet Neurology. 2016;15(12):1273-84.

3. Middleton S, Anakwe R. Carpal tunnel syndrome: clinical review. BMJ. 2014;349(g6437):1-7.

4. Franklin GM, Friedman AS. Work-related carpal tunnel syndrome: diagnosis and treatment guideline. Physical medicine and rehabilitation clinics of North America. 2015;26(3):523-37.

5. Zhu W, Ye Y, Liu Y, Wang XR, Shi GX, Zhang S, dkk. Mechanisms of acupuncture therapy for cerebral ischemia: an evidence-based review of clinical and animal studies on cerebral ischemia. Journal of Neuroimmune Pharmacology. 2017;12(4):575-92.

6. Aboonq MS. Pathophysiology of carpal tunnel syndrome. Neurosciences. 2015;20(1):4.

7. Rempel D, Evanoff B, Amadio PC, De-Krom M, Franklin G, Franzblau A, dkk. Consensus criteria for the classification of carpal tunnel syndrome in epidemiologic studies. American journal of public health. 1998;88(10):1447-51.

8. Bland JD. A neurophysiological grading scale for carpal tunnel syndrome. Muscle \& Nerve: Official Journal of the American Association of Electrodiagnostic Medicine. 2000;23(8):1280-3.

9. Putra Y. Uji validitas dan reliabilitas kuesioner Boston carpal tunnel syndrome questionnaire (BCTQ) versi Bahasa Indonesia [tesis]. Jakarta: Universitas Indonesia; 2018.

10. Maeda Y, Kettner N, Lee J, Kim J, Cina S, Malatesta C, dkk. Acupuncture-evoked response in somatosensory and prefrontal cortices predicts immediate pain reduction in carpal tunnel syndrome. EvidenceBased Complementary and Alternative Medicine. 2013;2013:13.

11. Maeda Y, Kettner N, Holden J, Lee J, Kim J, Cina $\mathrm{S}$, dkk. Functional deficits in carpal tunnel syndrome reflect reorganization of primary somatosensory cortex. Brain. 2014;137(6):1741-52.

12. Maeda Y, Kettner N, Sheehan J, Kim J, Cina S, Malatesta $\mathrm{C}$, dkk. Altered brain morphometry in carpal tunnel syndrome is associated with median nerve pathology. NeuroImage: Clinical. 2013;2:313-9.

13. Maeda Y, Kettner N, Kim J, Kim H, Cina S, Malatesta C, dkk. Primary somatosensory/motor cortical thickness distinguishes paresthesia-dominant from pain-dominant carpal tunnel syndrome. Pain. 2016;157(5):1085-93.

14. Maeda Y, Kim H, Kettner N, Kim J, Cina S, Malatesta $\mathrm{C}$, dkk. Rewiring the primary somatosensory cortex in carpal tunnel syndrome with acupuncture. Brain. 2017;140(4):914-27.

15. Maeda Y, Kettner N, Lee J, Kim J, Cina S, Malatesta $\mathrm{C}, \mathrm{dkk}$. Acupuncture evoked response in contralateral somatosensory cortex reflects peripheral nerve pathology of carpal tunnel syndrome. Medical acupuncture. 2013;25(4):275-84.

16. Kavoussi B, Ross BE. The neuroimmune basis of anti-inflammatory acupuncture. Integrative Cancer Therapies. 2007;6(3):251-7.

17. Shin HK, Lee SW, Choi BT. Modulation of neurogenesis via neurotrophic factors in acupuncture treatments for neurological diseases. Biochemical pharmacology. 2017;141:132-42.

18. Hadianfard M, Bazrafshan E, Momeninejad H, Jahani N. Efficacies of acupuncture and anti-inflammatory treatment for carpal tunnel syndrome. Journal of acupuncture and meridian studies. 2015;8(5):229-35.

19. Ural FG, Öztürk GT. The acupuncture effect on median nerve morphology in patients with carpal tunnel syndrome: an ultrasonographic study. EvidenceBased Complementary and Alternative Medicine. 2017;2017:5. 